HUNGARIAN AGRICULTURAL ENGINEERING

$N^{\circ} 37 / 2020$ 53-59

Published online: http://hae-journals.org/

HU ISSN 0864-7410 (Print) / HU ISSN 2415-9751(Online)

DOI: 10.17676/HAE.2020.37.53

Received: 10.11.2019. - Accepted: 10.02.2020
PERIODICAL OF THE COMITTEE OF

AGRICULTURAL AND BIOSYSTEM

ENGINEERING OF

THE HUNGARIAN ACADEMY OF SCIENCES

and

SZENT ISTVÁN UNIVERSITY

Faculty of Mechanical Engineering

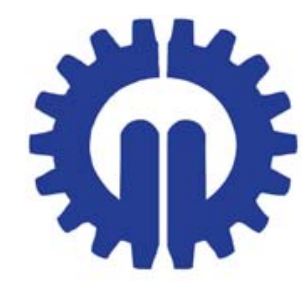

\title{
THE EFFECT OF IRRADIATION ON MEDIUM TEMPERATURE AND EC VALUES IN HYDROPONIC LONGTERM TOMATO CULTIVATION
}

\author{
Author(s): \\ T. Terbe ${ }^{1}$, M. Jancsó ${ }^{2}$, K. Mozsgai ${ }^{3}$, I. Rácz ${ }^{4}$ and S. B. Szantner ${ }^{5}$
}

\section{Affiliation:}

${ }^{1}$ Rudolt Fleischmann Research Institute, Eszterhazy Karoly University, Eszterhazy tér 1., Eger, H-3300, Hungary ${ }^{2}$ National Agricultural Research and Innovation Centre (NAIK), Research Institute of Irrigation and Water Management Anna Liget út 35., Szarvas, H-5540, Hungary

${ }^{3}$ Institute of Management and System Engineering, Faculty of Mechanical Engineering, Szent István University

Páter K. u. 1., Gödöllö, H-2103, Hungary

${ }^{4}$ Faculty of Agricultural and Economics Studies, Szent István University,

Szabadság út 1-3., Szarvas, H-5540, Hungary

${ }^{5}$ National Agricultural Research and Innovation Centre (NAIK), Vegetable Crop Research Department, Obermayer tér 9., Kalocsa, H-6300, Hungary

\section{Email address:}

terbe.tibor@uni-eszterhazy.hu, jancso.mihaly@ovki.naik.hu, mozsgai.katalin@fh.szie.hu, racz.istvanne@gk.szie.hu, schmidtne.barbara@zoko.naik.hu

\begin{abstract}
The yield results of long-term hydroponic tomato cultivation range from 40 to $70 \mathrm{~kg} / \mathrm{m}^{2}$, the productivity is significantly influenced by growing conditions. We investigate the effect of irradiation on rootzone temperature and $\mathrm{EC}$ values in a greenhouse technology. The irradiation data were provided by the climate controlled irrigation system, root zone temperature and EC values were monitored. During the whole examined period, there was no major fluctuation. Examination of the probe data on two selected days show that the change in EC values is not outstanding, but their overall value is considered to be very high compared to the usual 7-8 $\mathrm{mS} \mathrm{cm}^{-1}$ values.
\end{abstract}

Keywords: tomato, irradiation, hydroponic, temperature, EC

\section{Introduction}

Currently, tomato is forced in approximately 500 hectares in Hungary, approx. one-third of them are grown in modern greenhouses, almost exclusively using hydroculture technology. The yield results of long-term cultivation range from 40 to $70 \mathrm{~kg} / \mathrm{m}^{2}$, the productivity is significantly influenced by growing conditions and technology. High yields can be achieved through precise control (climate, physical/nutrient conditions of the growing medium, irrigation parameters, etc.) and optimal adjustment of environmental factors. Biomass production is induced by irradiation, but the physical/chemical characteristics of the root zone also have a significant effect on yield. The physical/chemical indexes of different growing media are known in the literature, but practical values are constantly changing due to environment-plant interactions.

\section{Literature review}

The physical and chemical parameters of the root zone have a significant impact on yields. In a hydroponic cultivation, the evolution of the root-zone salinity is monitored through the analysis of the drainage water. Drainage values can vary over a wide range, through the management of irrigation / nutrient solution and complex physiological processes. In hydroponic cultivation, salt accumulation is a common problem, which usually leads to yield depression, but can also have positive effects on fruit content. The effect of the high $\mathrm{EC}$ value in the root zone is that the fruit size decreases and the dry matter content increases. The rate of yield reduction is influenced by a number of factors, such as variety, environmental factors and nutrient management. 
Depending on environmental factors, salinity greater than 2.3-5.1 mS cm-1 causes yield reduction (Dorai et al., 2001). Irradiation directly influences the assimilation material available for crop production, increases the sugar / acid ratio in the fruits, increases the water uptake, and these together affect the EC value of the root zone. Some authors give different optimal EC values for different stages of generative development (Suhardiyanto et al., 2013).

Coconut fiber is a popular growing medium of organic origin. Particle size significantly affected the physical properties, especially the air-water relationships (Noguera et al., 2003). Coconut fiber is a water storage material with high moisture content (Kappel, 2008). Air filled pores provide easy warm-up, while high water content slows down warming. Irradiation quickly raises the temperature of the greenhouse, but at the same time the temperature of the root zone increases. Irrigation retards the temperature rise in the root zone and dilutes the solution, so the EC will decrease. The optimum temperature appears to be approximately $25{ }^{\circ} \mathrm{C}$ for uptake of the majority of mineral elements and all plant growth parameters (Tindall et al., 1990).

\section{Material and methods}

The crops involved in the experiment can be found in Szarvas, in the Galambos educational facility of St. István University. A greenhouse built in 2016 with almost 2,000 $\mathrm{m}^{2}$ gross and 1,800 $\mathrm{m}^{2}$ net area and $6 \mathrm{~m}$ height was used for the research. The greenhouse has two symmetric and separable areas, where it is possible to set different climatic conditions. The system for providing $\mathrm{CO}_{2}$ has also been installed. It consists of 12 connected bottles, so called bündels, which have electronic switch valves through which the level of $\mathrm{CO}_{2}$ can be regulated inside the greenhouse. Perforated KPE pipes with the diameter of $20 \mathrm{~mm}$ ensure the even distribution of carbon dioxide all along the rows.

The tomatoes were planted on January 24, 2019. The selected Aruba F1 variety has become one of the most popular vine tomatoes cultivated in Hungary during the past years. Its main positive features are the spectacular sepals, deep red colour and longevity. This latter characteristic is outstandingly important for commercial supermarket chains.

Seedlings were grown in 10 by $15 \mathrm{~cm}$ rockwool cubes in Szentes. They were transferred to the greenhouse when reaching six-leaves stage. Each rockwool cube has two plants to grow. These tomatoes were planted in a new growing medium of coconut fibre maintaining the density of 3.8 plants $/ \mathrm{m}^{2}$.

A climate computer operates in the greenhouse, making it possible to constantly record the measured data. Thus, inside radiation, temperature and air moisture at the top of the plants in both blocks of the greenhouse as well as $\mathrm{CO}_{2}$ concentration at $2 \mathrm{~m}$ height have been observed and recorded in 15-minute intervals during the entire production period. $\mathrm{CO}_{2}$ has been released into the greenhouse on an occasional basis in 2019.

During the experiment, from week 8 on the following data were continuously recorded: a) weekly growth, b) leaf length, c) number of leaves, d) leaf width, e) leaf area, f) stem diameter, g) vine distance, h) flowering vines, i) fruit setting vines and j) yield. These parameters were examined in both climate blocks involving 12 plants in four rows regarding each block.

In our study we used the climate computer's values of the average daily temperature, the daily amount of water irrigated and the daily total radiation. The probe was used by NAKI ÖVKI in the growing medium.

For hourly measurement of temperature $\left(\mathrm{T}^{\circ} \mathrm{C}\right)$ and electrical conductivity $(\mathrm{EC} \mathrm{mS} \mathrm{cm}-1)$ in the growing medium during the whole season, two sensors (TSC-06 and TSM-06, Boreas Ltd., Hungary) were installed in both blocks of the greenhouse. Both sensor types use time-domain reflectometry (TDR) technique. The TSM- 06 contains sensors for temperature (range $-40-+80^{\circ} \mathrm{C}$, accuracy $0.3^{\circ} \mathrm{C}$ ) measurements, while TSC-06 has EC (range 0-1000 mS/m, accuracy 2\% FSR) registration ability as well. Data were collected by automatic data loggers (EcoLogger-2, Boreas Ltd., Hungary) and transferred to the PC regularly. Data were analysed using MS Excel.

The evaluated period was from February 6 to August 31, 2019, where we compared the measured temperature values in the root zone medium and in the greenhouse as a function of irradiation, and the EC values of the irrigated nutrient with those of the EC values in the quilt.

The lowest and highest irradiated days in the period from May 15 to June 15 were also examined in 1-hour intervals. 
The two most important values of the test period were placed on the first figure (Fig. 1), which illustrates how precision cultivation can follow irrigation according to the needs of the plant throughout the growing year:

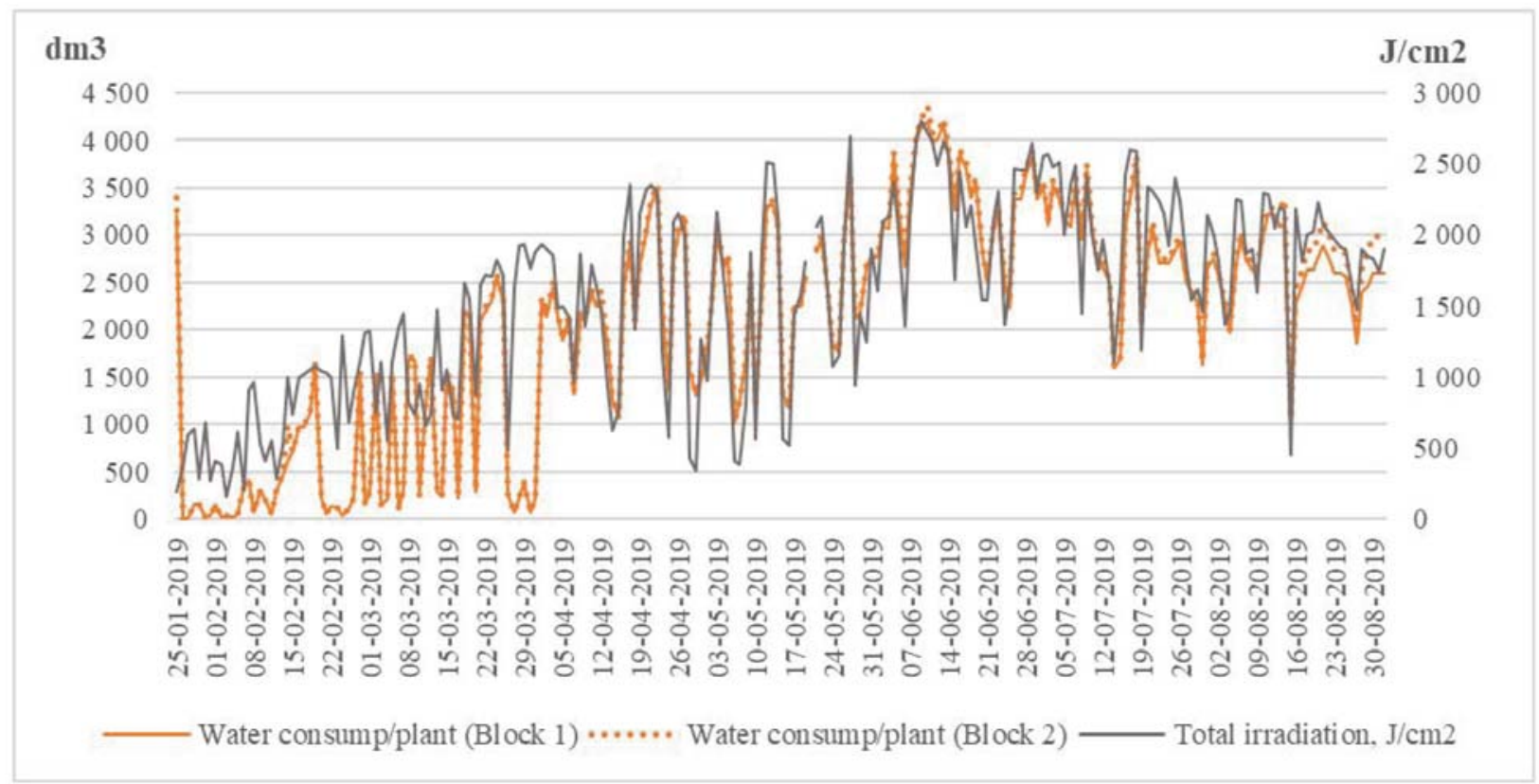

Figure 1. Relationship between water consumption and total irradiation

The figure (Fig. 1) illustrates the changes in extreme irradiation during the production year 2019, which the irrigation system was able to handle except for one or two technical failures. It is essential for modern cultivation to eliminate these problems as much as possible.

In the second figure (Fig. 2), the water consumption is compared with the internal temperature:

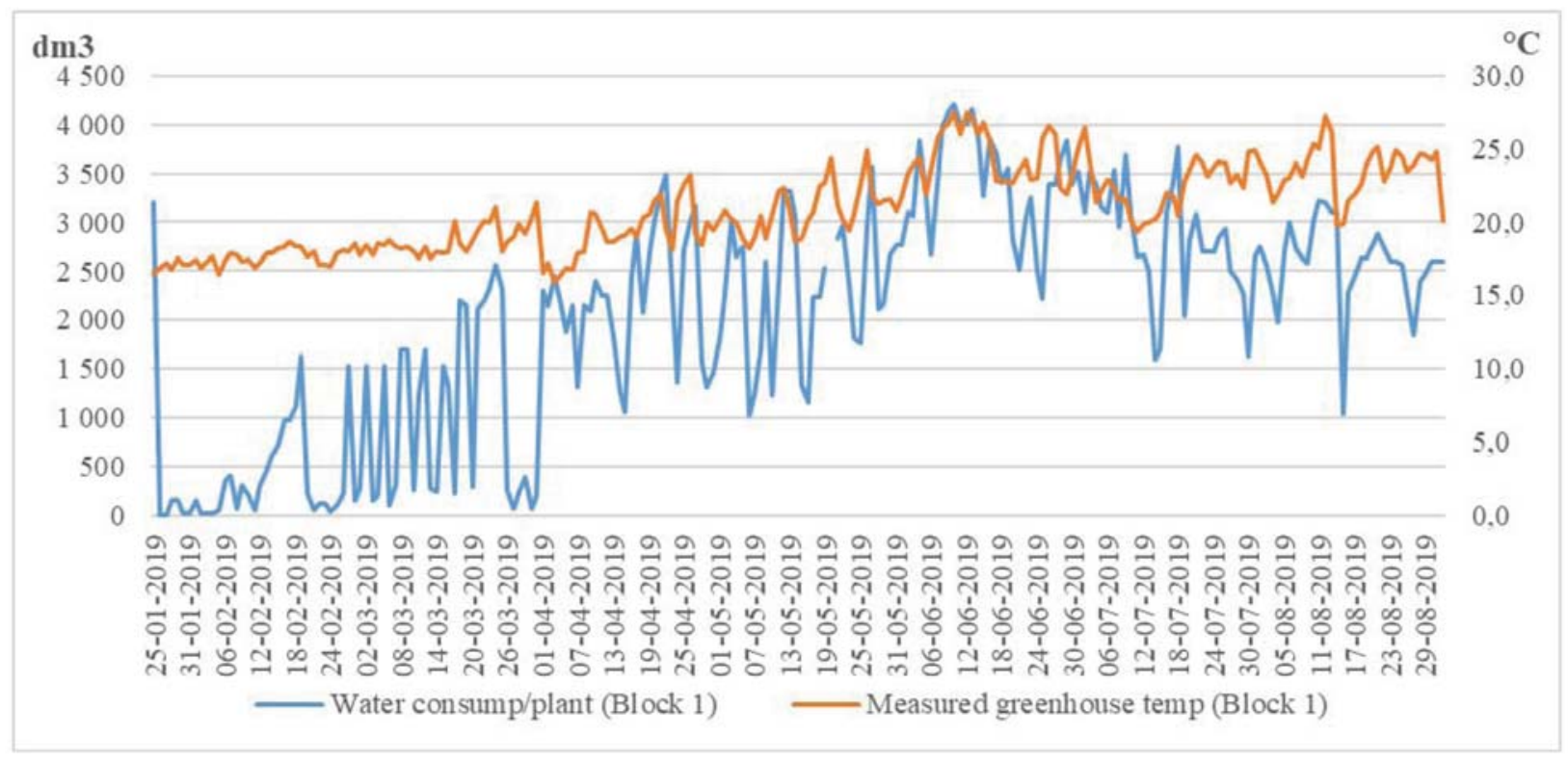

Figure 2. Water consumption and measured internal greenhouse temperature 
Heating in the greenhouse was not switched off during the test period, so water consumption and internal temperature are not related. The automatic heating system kept the set parameters in the early period (January April). The heating system operated during the summer to maintain the internal temperature even on cool, rainy days. The summer months (June-July) are characterized by a correlation between the amount of water applied and the internal temperature.

The following figure (Fig. 3) shows the water consumption and changes in the EC value of the irrigation water applied:

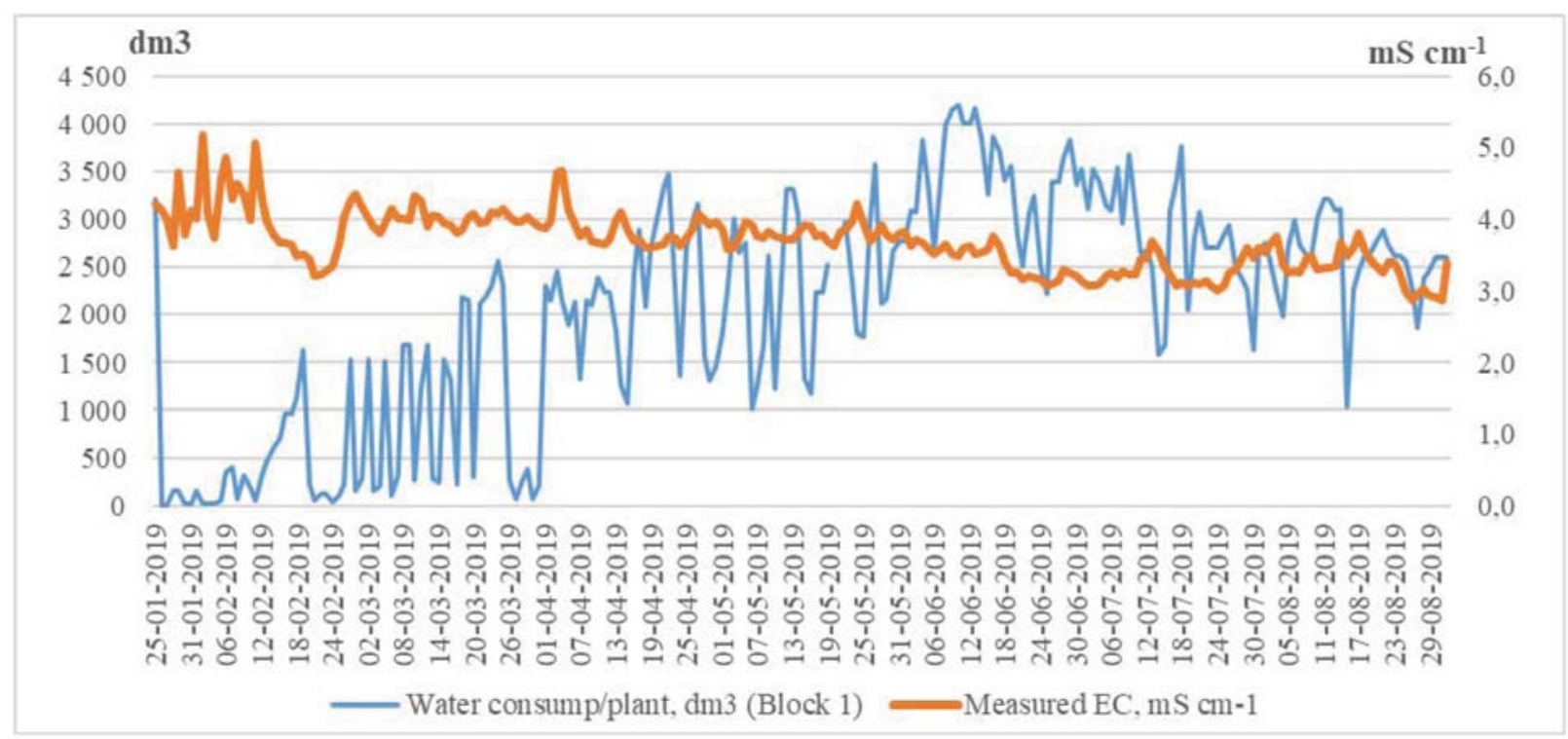

Figure 3. Water consumption and measured EC values of the irrigation water applied

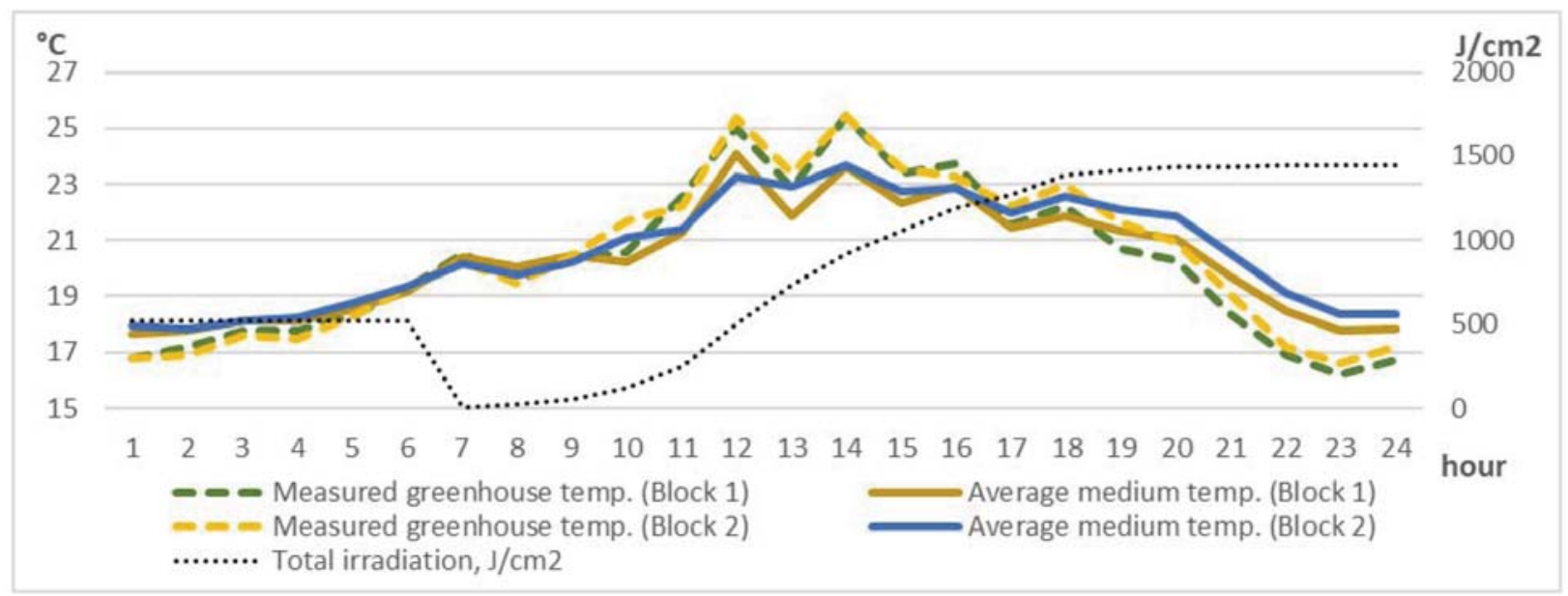

Figure 4. Changes in greenhouse air temperature and growing medium temperature, May 16, 2019

We can say that in today's modern cultivation, EC values are now $0.5-1 \mathrm{mS} \mathrm{cm}^{-1}$ higher than those described in the literature. During the growing year, it appears that the EC value of the irrigated water does not decrease proportionally with the amount of the irrigated water, and practically does not fall below $3 \mathrm{mS} \mathrm{cm}-1$ throughout the year. This also shows that as the irradiation increases, the water requirement increases proportionally, but the nutrient requirement is not followed. 
Changes in the EC and temperature of the growing quilt are shown on the day with the lowest and highest values of daily irradiation during the whole intensive growing period, May 15-June 15, 2019 (Fig. 4).

The lowest irradiation $\left(1441 \mathrm{~J} / \mathrm{cm}^{2}\right)$ was on May 16, which was a cloudy but not overcast day. The figure (Fig. 4) shows the data of the two separate climate block, the measured air and the medium temperatures.

It can be clearly seen in the figure (Fig.4.) that during the day the temperature of the air fluctuates by up to $8^{\circ} \mathrm{C}$, whereas in the case of quilts it changes only around $5{ }^{\circ} \mathrm{C}$. It is also noticeable that the difference between the two greenhouse blocks is minimal. In the late hours of the night, we can see that during the intense cooling phase, the air temperature in the greenhouse drops below the medium and stays there until dawn heating starts. This is explained by the water content of the medium at about $80 \%$, but it is noteworthy that the temperature of the root zone medium does not fall below $18^{\circ} \mathrm{C}$.

If we look at the change of the EC values of the root zone solution in the medium (Fig. 5), we see changes corresponding to the irrigation cycle and plant nutrient uptake. The balanced value drops during the intensive morning period, which the irrigation replaced only for 12 hours. With small swings, it reaches its original value at about 19-20 hours by the end of vegetation and shows a slight increase until midnight.

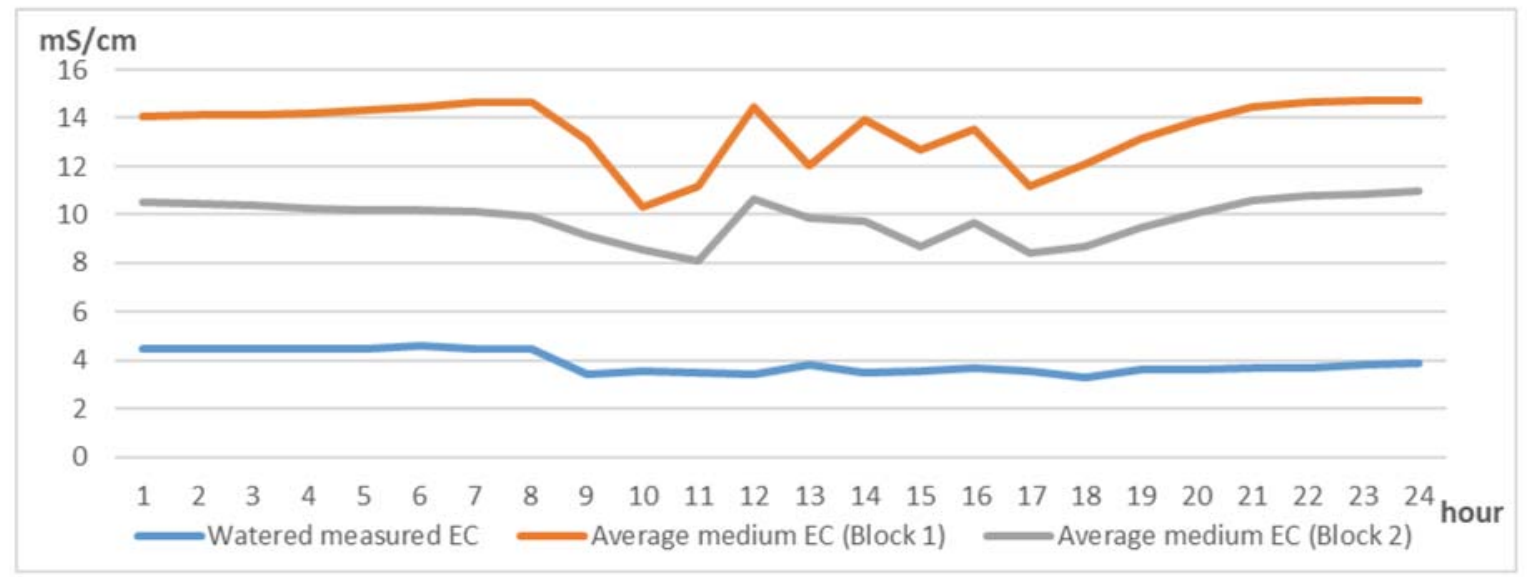

Figure 5. Changes of EC values in the root zone solution, coconut fiber medium May 16, 2019

The next selected day was June 9. (Fig. 6.), which was the highest daily irradiation day of the period with $2719 \mathrm{~J} / \mathrm{cm}^{2}$ value.

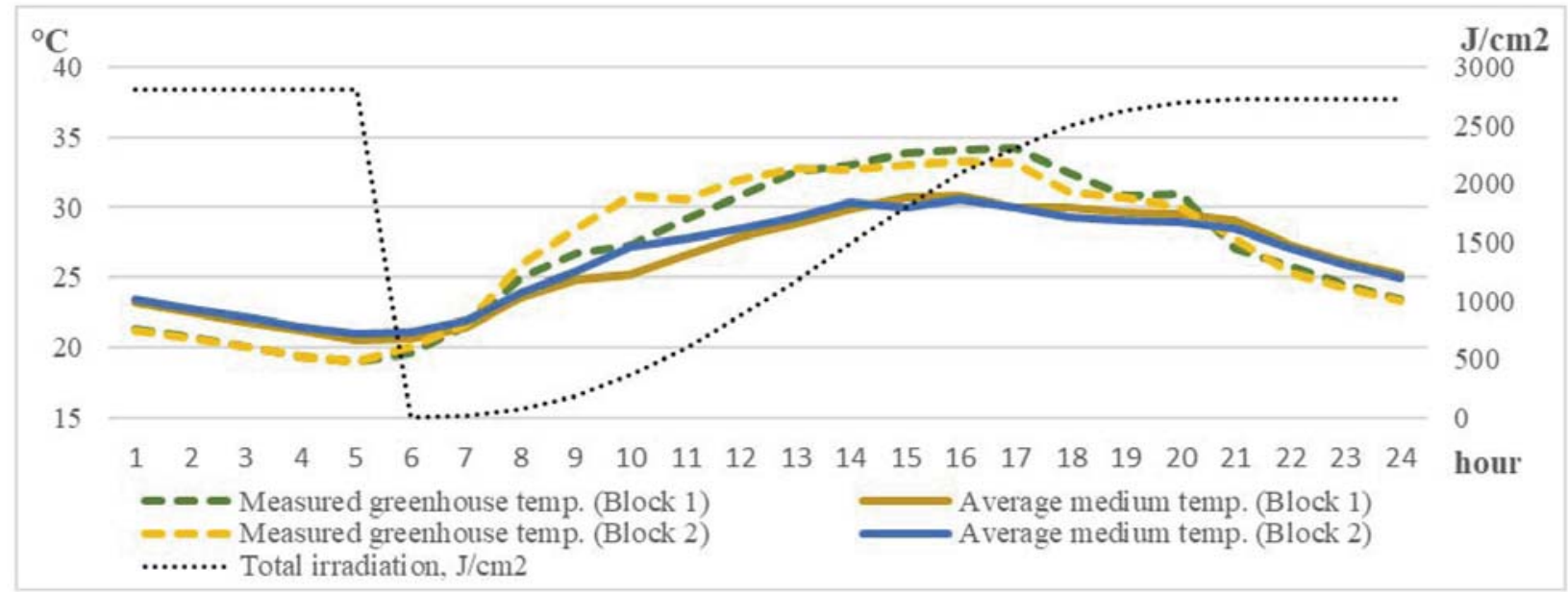

Figure 6. Changes in greenhouse air temperature and growing medium temperature, June 9, 2019 
It clearly shows that the daily temperature in the growing medium also exceeds $10^{\circ} \mathrm{C}$, however, the air temperature reaches $14^{\circ} \mathrm{C}$. During cultivation, it is desirable to keep the temperature of the medium below $25^{\circ} \mathrm{C}$, which in this case could not be achieved between 9 and 23 hours. This did not pose a significant problem in cultivation, but in such a case greater attention should be paid to the proper use of water.

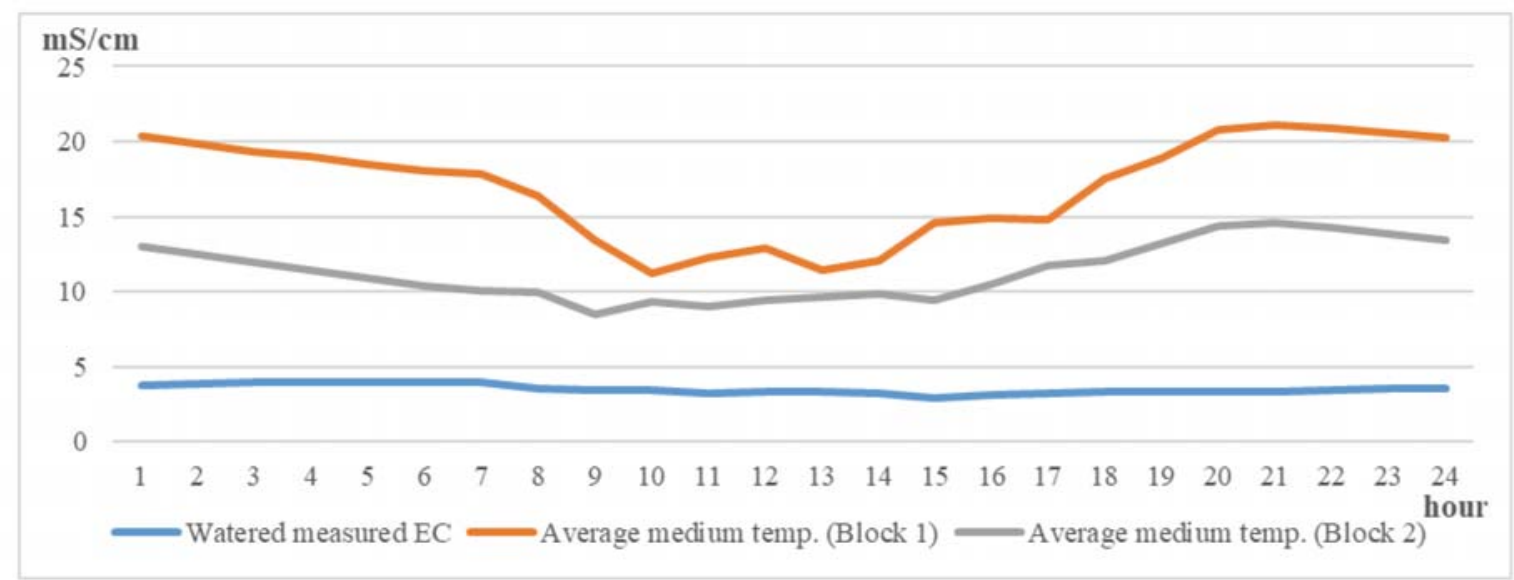

Figure 7. Changes of EC values in the root zone solution, coconut fiber medium, June 09, 2019

If we look at the change in EC values (Fig. 7.), we can see that its daily course is practically the same as in May, only the values have changed. It should be noted that EC values on both days were extremely high in the quilt, probably due to the low amount of irrigation water applied. The EC value of 3.5-4 mS cm-1 of the applied medium is also high compared to the practical experience of the indicated period.

\section{Conclusions}

It can be stated that with modern cultivation equipment the amount and the exact dosing of nutrient solution to be applied can be solved in time with today's control systems. During the whole examined period, there was no major fluctuation and no longer problem with the irrigation system or the climate control. Examination of the probe data and the two selected days show that the change in EC values is not outstanding, but their overall value is considered to be very high compared to the usual $7-8 \mathrm{mS} \mathrm{cm}^{-1}$ values in practise. Further studies are needed to clarify this, but since the EC change value is not high, it will be necessary to increase the amount of irrigated water in general and also recommended to reduce the $\mathrm{EC}$ value of the irrigated nutrient solution in subsequent growing seasons.

In the present case, these values did not cause significant or obvious damage to the herd, but in later periods nutrient uptake disturbances may occur, e.g. Ca deficiency.

\section{Summary}

In our experimental work, we investigate the effect of irradiation on root-zone temperature and EC values in a long-term greenhouse technology, with open system water management, used coconut fiber as growing medium and planted on January 24. The irradiation data were provided by the climate controlled irrigation system. Root zone temperature and EC values were monitored, 1-1 plants were measured in two different climates (left and right parts of greenhouse) between 6 February and 23 August. The probes collected hourly data during the period under study. Statistical methods were used to evaluate the data. We examined the relationship between the daily dynamics and the measured data, evaluated the data against the optimal values, and examined the development of trends. We have tried to explain the major fluctuations in other technological circumstances. 


\section{Acknowledgement}

This publication has been completed within the framework of project no. EFOP-3.6.1-16-2016-00016 focusing on training and research profiles with intelligent specializations on the Szarvas Campus of St. Istvan University involving agricultural water management, hydroponic plant systems, alternative crop production related to improving precision machinery in agriculture.

\section{References}

[1] Kappel, Noémi (2008): A talaj nélküli termesztésben használatos közegek és elhelyezésük. In: Terbe Slezák szerk. (2008): Talaj nélküli zöldséghajtatás. Mezőgazda Kiadó, Budapest,

[2] Martine Dorai, Athanasios Papadopoulos, André Gosselin (2001): Influence of electric conductivity management on greenhouse tomato yield and fruit quality. Agronomie, EDP Sciences, 21 (4), pp.367-383.

[3] Patricia Noguera, Manuel Abad, Rosa Puchades, Angel Maquieira, Vicente Noguera (2003): Influence of Particle Size on Physical and Chemical Properties of Coconut Coir Dust as Container Medium, Communications in Soil Science and Plant Analysis, 34:3-4, 593-605,

[4] Suhardiyanto, Herry; Arif, Chusnul; Setiawan, Budi I.. (2013): Optimization of EC Values of Nutrient Solution for Tomato Fruits Quality in Hydroponics System Using Artificial Neural Network and Genetic Algorithms. Journal of Mathematical and Fundamental Sciences, [S.1.], v. 41, n. 1, p. 38-49, Jul.

[5] James A. Tindall, H.A. Mills, D.E. Radcliffe (1990): The effect of root zone temperature on nutrient uptake of tomato, Journal of Plant Nutrition, 13:8, 939-956, 